\title{
Distribution of Peripheral Arterial Disease in Patients Undergoing Endovascular Revascularization for Chronic Limb Threatening lschaemia: Insights from the Vascular Quality Initiative in Singapore
}

\author{
Shereen X. Y. Soon ${ }^{1}$, Ankur Patel ${ }^{2}$, Tze Tec Chong ${ }^{1,3}$, Charyl J. Q. Yap ${ }^{1}$, Hsien Ts'ung Tay ${ }^{1}$, \\ Kiang Hiong Tay $^{2}$, Chandramohan Sivanathan ${ }^{2}$, and Tjun Y. Tang ${ }^{1,3}$ \\ ${ }^{1}$ Department of Vascular Surgery, Singapore General Hospital, Singapore, ${ }^{2}$ Department of Vascular and Interventional Radiology, \\ Singapore General Hospital, Singapore, ${ }^{3}$ Duke NUS Medical Graduate School, Singapore
}

\begin{abstract}
This study aimed to examine the distribution of lower limb atherosclerotic lesions in a multi-ethnic Asian cohort with chronic limb threatening ischemia (CLTI) from Singapore. The Society for Vascular Surgery Vascular Quality Initiative registry database was used to identify $265 \mathrm{CLTl}$ patients who underwent percutaneous angioplasty between June 2019 and December 2019, of whom 171 (64.5\%) were male, and the mean age was $67.9 \pm 11.0$ years. The majority were diabetic (84.5\%) and 145 (54.7\%) had chronic kidney disease (CKD). The majority of the lower limb atherosclerotic lesions were de novo lesions (598/797, 75.0\%), predominantly TransAtlantic Inter-Society Consensus II C/D (451/797, 56.6\%), and were moderately to severely calcified (76.3\%). The anterior tibial artery and femoral-popliteal artery were the most commonly affected vessels. The mean length of the treated lesions was $14.5 \pm 13.7 \mathrm{~cm}$. There was a tendency, albeit insignificant, of multi-level disease in those who were diabetic or had CKD.
\end{abstract}

Key Words: Angioplasty, Peripheral arterial disease, Lower extremity, lschemia, Singapore
Received March 2, 2021

Revised April 22, 2021

Accepted May 10, 2021

Published on June 11, 2021

Corresponding author: Tjun Y. Tang

Department of Vascular Surgery, Singapore General Hospital, Academia 20 College Road, Singapore 169856, Singapore

Tel: 65-63214007

Fax: 65-62209323

E-mail: tang.tjun.yip@singhealth.com.sg https://orcid.org/0000-0002-8524-7912

Copyright (c) 2021 The Korean Society for Vascular Surgery

This is an Open Access article distributed under the terms of the Creative Commons Attribution Non-Commercial License (http://creativecommons.org/licenses/by-nc/4.0) which permits unrestricted non-commercial use, distribution, and reproduction in any medium, provided the original work is properly cited.

Vasc Specialist Int • https://doi.org/10.5758/vsi.210016

\section{INTRODUCTION}

Chronic limb-threatening ischemia (CLTI), the most severe stage of peripheral arterial disease (PAD), is characterized by atherosclerotic occlusion of the lower extremity arteries with pain at rest, gangrene, and ulceration for more than two weeks. When left untreated, it can lead to major lower extremity amputation (LEA), reduced quality of life, and increased mortality. A 2019 systematic review found that the global estimates of individuals with PAD above the age of 25 years were 236 million in 2015 [1]. Advanced age, smoking, hypertension, and cardiovascular diseases were also associated with a higher risk of PAD. The majority of the included studies consisted mainly of Caucasian cohorts, indicating a lack of data on PAD in the Asian population.

The prevalence of PAD in Asian cohorts is reported to be 6\%-10\% [2]. The Singapore Reduction of Atherothrombosis for Continued Health (REACH) registry estimated that PAD affected $8.1 \%$ of the local population in 2008, with a mean age of $64.4 \pm 9.8$ [3]. The PAD cohort in Singapore is frailer than its Western counterparts, with a high proportion of patients with concomitant comorbidities, such as diabetes mellitus, chronic kidney disease (CKD), and congestive heart failure [2]. These comorbidities may contribute to the late 
diagnosis and treatment of PAD, increased healthcare costs, and a higher incidence of adverse outcomes. PAD prevalence also increases with age $(20 \%$ at 40 years of age to $29 \%$ in those aged over 50 years). Hence, PAD contributes to frailty in the growing local population.

The Society for Vascular Surgery (SVS) Vascular Quality Initiative (VQI) is an ongoing prospective international registry consisting of detailed clinical data on common vascular procedures. The VQI was designed to improve patient care through the dissemination of information, streamlining variations in practices, and international benchmarking guidelines for vascular surgical practices. Centers enrolled in the VQ1 were reported to receive biannual "Center Opportunity Profiles for Improvement" reports, which consolidate procedural outcomes into actionable center-level data to improve patient care. As of January 2021, more than 360 peer-reviewed publications have been published from the SVS VQI documenting regional demographic variations and outcomes for quality improvement in vascular surgery. Consisting of 750 participating institutions, including academic medical centers, teaching hospitals, and individual clinics across the United States and Canada, our local vascular center joined this collaboration 18 months ago and is the first and only Asian-based vascular center to contribute to this growing United States-based vascular registry.

This study aimed to highlight the demographics and distribution of lower limb anatomical arterial occlusive lesions in patients with localized PAD who are undergoing endovascular revascularization.

\section{METHODS}

This was a retrospective observational study of the SVSVQ1 registry. Modeled after the Vascular Study Group of New England (www.vqi.org), the goal of VQ1 is to utilize aggregated data to recognize variations in procedures and outcomes through the collaboration of regional quality groups. It is a web-based data collection platform that captures a range of variables, such as patient demographics and clinical, perioperative, and postoperative details. Between January 2018 and December 2020, there were a total of 108,960 percutaneous vascular interventions registered in the VQI registry across 793 participating centers. This study was approved by the SingHealth Centralised Institutional Review Board (CIRB number: 2018/2995). Patient consent was waived, given the deidentified nature of the data.

The VQI database was used to identify CLTI patients who underwent lower limb angioplasty for limb salvage between June 2019 and December 2019 at our local hospital, a tertiary vascular center located in central Singapore. We perform over 900 lower limb salvage procedures annually. Of these, 95\% are for CLT1 (Rutherford 5-6). The institution has adopted an endovascular-first approach since 2005 and has performed approximately 10-15 surgical bypasses per year for failed endovascular revascularization. All patients who underwent elective, urgent, or emergency percutaneous transluminal angioplasty (PTA) were included (Elective, planned; Urgent, required within 72 hours after 12 hours of admission; Emergency, required within 12 hours of admission). We reviewed patient demographics, comorbidities, clinical history, symptoms, lesions, and perioperative details. Data forms, the definitions of comorbidities, and procedural details within the VQI are available online at www. vqi.org.

The variables were summarized using descriptive statistics. Categorical data are reported as numbers and percentages. Continuous variables are reported as means and standard deviations. Univariate analysis for categorical and continuous variables was performed using the chi-squared test and Mann-Whitney U-test, respectively. Statistical significance was set at $P<0.05$. All statistical analyses were performed using R version 1.3.1 (R Development Core Team, 2013; http://www.r-project.org/).

\section{RESULTS}

A total of 291 procedures were identified, and 265 patients (294 limbs) were included, of whom 171 (64.5\%) were males, and the mean age was $67.9 \pm 11.0$ years. The majority of the patients were Chinese $(175,66.0 \%)$, diabetic $(224 / 265$, $84.5 \%)$, hypertensive $(240,90.6 \%)$, and had a history of coronary artery disease (156/265, 58.9\%) and CKD (145/265, 54.7\%). Baseline demographics are shown in Table 1.

The majority of wounds were Rutherford 6 (192/294, 65.3\%), followed by 40/294 (13.6\%) Rutherford 5 (nonhealing amputation wounds), and 26/294 (8.8\%) with ischemic pain at rest (Table 2) [4]. The mean Wound, Ischemia, and foot Infection (WIfl) score was 3.02 \pm 1.98 , and the mean toe pressure was $43.5 \pm 26.9 \mathrm{mmHg}$. Risk stratification based on Wifl scores showed that 115/294 (39.1\%) limbs were at moderate to high risk of amputation (majority>wound 1, ischemia 2, foot infection 2).

A total of 797 lesions were treated. The majority were de novo lesions (598/797, 75.0\%). The majority of lesions were TransAtlantic Inter-Society Consensus 11 (TASC 11) C and D (25.2\% and $31.4 \%$, respectively). Most were moderately to severely calcified (608/797, 76.3\%) (Table 3). The anterior tibial artery and the femoral-popliteal artery were the most commonly treated vessels (168/797, 21.1\% and 103/797, $12.9 \%$, respectively). The mean length of the treated lesions was $14.5 \pm 13.7 \mathrm{~cm}$. The majority of lesions were multi-level 
Table 1. Patient demographics

\begin{tabular}{|c|c|}
\hline Characteristic & Patient $(n=265)$ \\
\hline Age, years & $67.9 \pm 11.0$ \\
\hline Body mass index, $\mathrm{kg} / \mathrm{m}^{2}$ & $20.2 \pm 4.0$ \\
\hline \multicolumn{2}{|l|}{ Sex } \\
\hline Male & $171(64.5)$ \\
\hline Female & $94(35.5)$ \\
\hline \multicolumn{2}{|l|}{ Ethnic group } \\
\hline Chinese & $175(66.0)$ \\
\hline Malay & $39(14.7)$ \\
\hline Indian & $45(17.0)$ \\
\hline Eurasian & $3(1.1)$ \\
\hline Indonesian & $1(0.4)$ \\
\hline Caucasian & $1(0.4)$ \\
\hline Myanmar & $1(0.4)$ \\
\hline \multicolumn{2}{|l|}{ Smoking status } \\
\hline Non-smoker & $162(61.1)$ \\
\hline Smoker & $57(21.5)$ \\
\hline Ex-smoker & $46(17.4)$ \\
\hline \multicolumn{2}{|l|}{ Comorbidities } \\
\hline Diabetes & $224(84.5)$ \\
\hline Hypertension & $240(90.6)$ \\
\hline Coronary artery disease & $156(58.9)$ \\
\hline Chronic kidney disease & $145(54.7)$ \\
\hline On dialysis & $87(32.8)$ \\
\hline Cerebrovascular disease & $68(25.7)$ \\
\hline Dysrhythmia & $53(20.0)$ \\
\hline Congestive heart failure & $46(17.4)$ \\
\hline Chronic obstructive pulmonary disease & $11(4.2)$ \\
\hline \multicolumn{2}{|l|}{ Chronic medications } \\
\hline Pre ACE-inhibitor/ARB & $264(99.6)$ \\
\hline Statin & $234(88.3)$ \\
\hline Antiplatelets & $216(81.5)$ \\
\hline \multicolumn{2}{|l|}{ Prior interventions } \\
\hline Leg arterial bypass/endarterectomy/PVI & $131(49.4)$ \\
\hline Percutaneous coronary intervention & $64(24.2)$ \\
\hline Coronary artery bypass graft & $58(21.9)$ \\
\hline
\end{tabular}

Values are presented as mean \pm standard deviation or number (\%). $A C E$, angiotensin-converting enzyme; $A R B$, angiotension receptor blocker; PVI, peripheral vascular intervention.

(194/294 limbs, 66.0\%) and distributed amongst the femoropopliteal and tibial regions (172/294 limbs, 58.5\%). There were also 68/797 (8.5\%) lesions that were inframalleolar.

Subgroup comparisons between diabetics and nondiabetics showed a higher distribution of severely calcified, multi-level, TASC $11 \mathrm{C}$ lesions among diabetics (severely calcified $39.5 \%$ vs. $29.4 \%, P=0.046$; multi-level $59.8 \%$ vs. 52.1\%, $\mathrm{P}=0.408$; TASC $11 \mathrm{C} 27.4 \%$ vs. $12.6 \%, \mathrm{P}<0.001)$. In-
Table 2. Indications for intervention

\begin{tabular}{|c|c|}
\hline Reason for intervention & $\operatorname{Limb}(n=294)$ \\
\hline \multicolumn{2}{|l|}{ Side } \\
\hline Right & $153(52.0)$ \\
\hline Left & $141(48.0)$ \\
\hline \multicolumn{2}{|l|}{ Prior interventions } \\
\hline Angioplasty (ipsilateral) & $111(37.8)$ \\
\hline \multicolumn{2}{|l|}{ Amputations } \\
\hline Minor (leg, foot, toe) & $66(22.4)$ \\
\hline Major contralateral (AKA, BKA) & $23(7.8)$ \\
\hline Femoral endarterectomy & $6(2.0)$ \\
\hline \multicolumn{2}{|l|}{ Urgency } \\
\hline Urgent & $209(71.1)$ \\
\hline Elective & $75(25.5)$ \\
\hline Emergency & $10(3.4)$ \\
\hline \multicolumn{2}{|l|}{ Rutherford classification } \\
\hline 6 (necrotic ulcer) & $192(65.3)$ \\
\hline 5 (non-healing amputation) & $40(13.6)$ \\
\hline 4 (ischemic rest pain) & $26(8.8)$ \\
\hline 3 (claudication) & $32(10.9)$ \\
\hline 0 (asymptomatic) & $4(1.4)$ \\
\hline Wound, Ischemia, and foot Infection score & $3.02 \pm 1.98$ \\
\hline Toe pressure, mmHg & $43.5 \pm 26.9$ \\
\hline \multicolumn{2}{|l|}{ Risk of amputation ${ }^{\text {a }}$} \\
\hline 1 (very low risk) & $104(35.4)$ \\
\hline 2 (low risk) & $75(25.5)$ \\
\hline 3 (moderate risk) & $46(15.6)$ \\
\hline 4 (high risk) & $69(23.5)$ \\
\hline Multi-level disease & 194 (66.0) \\
\hline FP+tibial & $172(58.5)$ \\
\hline $\mathrm{Iliac+FP}$ & $14(4.8)$ \\
\hline Iliac+FP+tibial & $8(2.7)$ \\
\hline
\end{tabular}

Values are presented as number (\%) or mean \pm standard deviation. AKA, above-the-knee; BKA, below-the-knee; FP, femoral-popliteal. ${ }^{a}$ Risk of amputation according to Wound, Ischemia, and foot Infection category derived from the article of Mills et al. (J Vasc Surg 2014;59:220-234.e1-2) [4].

terestingly, there was a significantly higher proportion of TASC $11 \mathrm{D}$ and iliac artery lesions among patients who were non-diabetic (TASC 11 D, non-diabetes mellitus (DM) 42.9\% vs. DM $29.4 \%, P=0.005$; iliac artery, non-DM 9.2\% vs. DM $2.8 \%, \mathrm{P}=0.002$ ). There was also a higher proportion of diseased multi-level femoropopliteal-tibial lesions among patients with diabetes and patients with CKD, though this difference was non-significant (DM 59.8\% vs. non-DM 52.1\%, $\mathrm{P}=0.408$; CKD 62.5\% vs. non-CKD 53.7\%, $\mathrm{P}=0.161$ ) (Fig. 1). 
Table 3. Distribution of lesions between diabetics and non-diabetic subgroups

\begin{tabular}{|c|c|c|c|c|}
\hline Characteristic & Total $(n=797)$ & Diabetic $(n=678)$ & Non-diabetic $(n=119)$ & P-value \\
\hline \multicolumn{5}{|l|}{ Technical success } \\
\hline Successful (stenosis $\leq 30 \%$ ) & $733(92.0)$ & $630(92.9)$ & $103(86.6)$ & \multirow[t]{3}{*}{0.053} \\
\hline Technical failure & $42(5.3)$ & $32(4.7)$ & $10(8.4)$ & \\
\hline Stenosis $>30 \%$ & $22(2.8)$ & $16(2.4)$ & $6(5.0)$ & \\
\hline Lesion length, $\mathrm{cm}$ & $14.5 \pm 13.7$ & $14.5 \pm 13.9$ & $14.9 \pm 12.6$ & 0.446 \\
\hline De novo lesion & $598(75.0)$ & $506(74.6)$ & $92(77.3)$ & 0611 \\
\hline \multicolumn{5}{|l|}{ Re-stenotic } \\
\hline Prior angioplasty & $167(21.0)$ & $151(22.3)$ & $16(13.4)$ & \\
\hline Prior stenting & $32(4.0)$ & $21(3.1)$ & $11(9.2)$ & \\
\hline \multicolumn{5}{|l|}{ TASC II } \\
\hline A & $133(16.7)$ & $114(16.8)$ & $19(16.0)$ & 0.924 \\
\hline B & $213(26.7)$ & $179(26.4)$ & $34(28.6)$ & 0.703 \\
\hline C & $201(25.2)$ & $186(27.4)$ & $15(12.6)$ & $<0.001$ \\
\hline D & $250(31.4)$ & $199(29.4)$ & $51(42.9)$ & 0.005 \\
\hline \multicolumn{5}{|l|}{ Calcification } \\
\hline Severe & $303(38.0)$ & $268(39.5)$ & $35(29.4)$ & 0.046 \\
\hline Moderate & $305(38.3)$ & $266(39.2)$ & $39(32.8)$ & 0.217 \\
\hline Mild & $122(15.3)$ & 105 (15.5) & $17(14.3)$ & 0.843 \\
\hline Focal & $52(6.5)$ & $29(4.3)$ & $23(19.3)$ & $<0.001$ \\
\hline None & $15(1.9)$ & $10(1.5)$ & $5(4.2)$ & 0.076 \\
\hline \multicolumn{5}{|l|}{ Lesion location } \\
\hline Anterior tibial artery & $168(21.1)$ & $148(21.8)$ & $20(16.8)$ & 0.264 \\
\hline SFA+popliteal & $103(12.9)$ & $84(12.4)$ & $19(16.0)$ & 0.355 \\
\hline SFA & $98(12.3)$ & $82(12.1)$ & $16(13.4)$ & 0.793 \\
\hline Posterior tibial artery & $93(11.7)$ & $78(11.5)$ & $15(12.6)$ & 0.849 \\
\hline Tibioperoneal trunk & $75(9.4)$ & $64(9.4)$ & $11(9.2)$ & $>0.999$ \\
\hline Popliteal & $70(8.8)$ & $62(9.1)$ & $8(6.7)$ & 0.484 \\
\hline Peroneal & $69(8.7)$ & $60(8.8)$ & $9(7.6)$ & 0.777 \\
\hline Dorsalis pedis artery & $47(5.9)$ & $43(6.3)$ & $4(3.4)$ & 0.288 \\
\hline Iliac artery & $30(3.8)$ & $19(2.8)$ & $11(9.2)$ & 0.002 \\
\hline Common plantar artery & $21(2.6)$ & $20(2.9)$ & $1(0.8)$ & 0.346 \\
\hline Common femoral artery & $18(2.3)$ & $14(2.1)$ & $4(3.4)$ & 0.328 \\
\hline Profunda artery & $5(0.6)$ & $4(0.6)$ & $1(0.8)$ & 0.555 \\
\hline
\end{tabular}

Values are presented as number (\%) or mean \pm standard deviation.

TASC II, TransAtlantic Inter-Society Consensus II; SFA, superficial femoral artery.

\section{DISCUSSION}

Within the vascular field, the VQ1 is a useful tool for understanding regional cohort outcomes and quality improvement. Thus far, studies reporting outcomes from the VQI database largely examine vascular procedures such as carotid endarterectomy, lower extremity bypass, and aortic aneurysms. The outcomes of endovascular treatments are also largely targeted to the Western populations, leaving a gap in our understanding of the Asian endovascular cohorts. This study demonstrated the distribution of demo- graphics and diseased lesions in Asian patients undergoing endovascular revascularization for PAD. Comparing to the endovascular Western cohorts from the SVS VQI registry [5], the Asian CLTl patient population was more complex, presenting with a higher incidence of comorbidities (84.5\% vs. $56.2 \%$ diabetics, $54.7 \%$ vs. $8.2 \%$ CKD, respectively), a higher proportion of severely diseased lesions $(78.9 \%$ vs. $22.5 \%$ TASC C-D, respectively), along with a higher proportion of patients with tissue loss (78.9\% vs. $27.6 \%$, respectively). The Singaporean (SG) cohort also appeared to have more comorbidities at baseline than their Asian counterparts in 


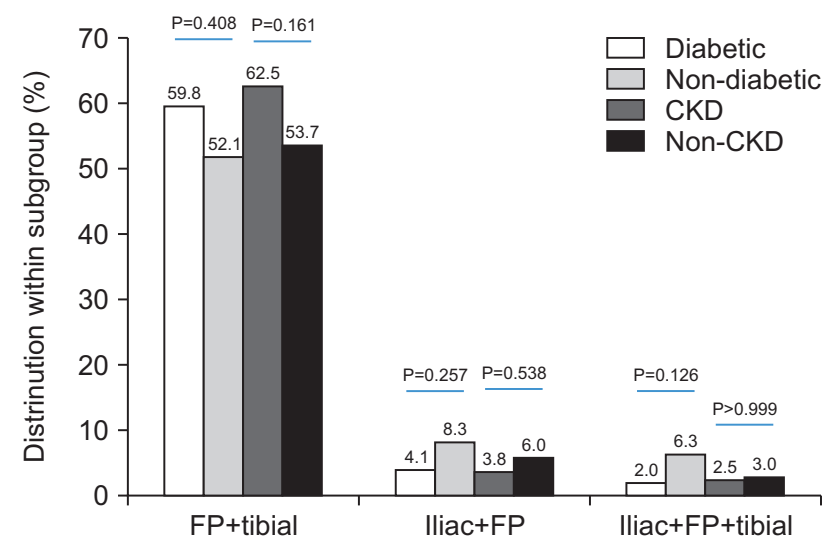

Fig. 1. Distribution of multi-level lesions across subgroups. CKD, chronic kidney disease; FP, femoral-popliteal.

Taiwan (TW) and Japan (JP) (diabetes: SG 84.5\%, TW 81\%, JP 68\%; hypertension: SG 90.6\%, TW 85\%, JP 81\%) [6]. Comparing to data from the 2008 REACH registry, it is also evident that PAD is presenting later within the local population (mean age in 2008: $64.4 \pm 9.8$ years vs. mean age in 2019: $67.9 \pm 11.0$ years) [3]. This has impacted clinical practice, as physicians have shifted to an endovascular approach instead of the more invasive open surgical bypass option since older patients are generally frailer and more adverse to procedures involving larger incisions and greater trauma [2].

Despite varying demographics and comorbidities, and consistent with our findings, published evidence supports the hypothesis that patients with diabetes are significantly less likely to have disease in the aortoiliac segment, and more likely to have multi-level diseases and atherosclerotic disease in the tibial vessels [7]. These findings can be attributed to several metabolic consequences of diabetes, such as advanced glycation, changes in low-density lipoprotein cholesterol, abnormal oxidative stress, and platelet activation. Diabetes and its influence on the distribution of atherosclerotic disease are related to poorer outcomes following revascularization procedures. Park et al. [8] demonstrated that patients with diabetes had higher proportions of femoral and below-the-knee lesions and displayed a higher rate of major adverse limb events, especially below the ankle amputations. Furthermore, patients with PAD and diabetes are also more susceptible to microvascular diseases (neuropathy, retinopathy, nephropathy) that cannot be treated by angioplasties as PTA would only restore macrocirculation, resulting in poorer outcomes, such as failure of wound healing post-intervention. The majority of the diabetic lesions treated were also multi-level and extremely severe (65.4\% multi-level, 56.8\% TASC 11 C-D). Such occluded distal vessels are often too small to bypass onto, resulting in the need for a larger bypass conduit, further revascularization, or major LEAs.

The clinical benefits of understanding the demographic and anatomical distribution of these lesions are twofold. First, it allows for more streamlined preoperative risk stratification and multidisciplinary optimization to improve periprocedural outcomes. A retrospective analysis of risk factors for immediate technical failure, such as the inability of the guidewire to cross a chronic occlusion, followed patients who had endovascular treatment for femoral-popliteal occlusive lesions and showed that ostial occlusion and heavy calcification of the superior femoral artery and popliteal artery were negative predictors [9]. Predictive models based on these findings may aid physicians in performing an adequate endovascular revascularization procedure in a realistic timeframe. Second, preoperative knowledge of the anatomical distribution of lesions allows for better management of patient and caregiver expectations on wound healing and functional outcomes. TASC $11 \mathrm{C} / \mathrm{D}$ infrapopliteal lesions are associated with higher major LEA and lower primary patency than are TASC A/B infrapopliteal lesions [10]. Thus, early recognition of the potential loss of ambulation status among these complex patients could aid in decision making, including whether the revascularization or major amputation-first policy should be instituted, thereby allowing for better management of postoperative functional outcomes.

\section{CONCLUSIONS}

This local Asian CLTl cohort presented with multi-level atherosclerotic disease with long, highly calcified stenotic segments, contrary to our western counterparts [5]. Understanding the underlying chronic comorbidities, such as diabetes and CKD, that contribute to varying PAD severity at presentation may impact decision making for a revascularization- or amputation-first policy and assist in the prediction of realistic postoperative outcomes.

\section{CONFLICTS OF INTEREST}

The authors have nothing to disclose.

\section{ORCID}

Shereen X. Y. Soon

https://orcid.org/0000-0003-3057-5983

Ankur Patel

https://orcid.org/0000-0002-7595-7048

Tze Tec Chong

https://orcid.org/0000-0001-5927-4303 


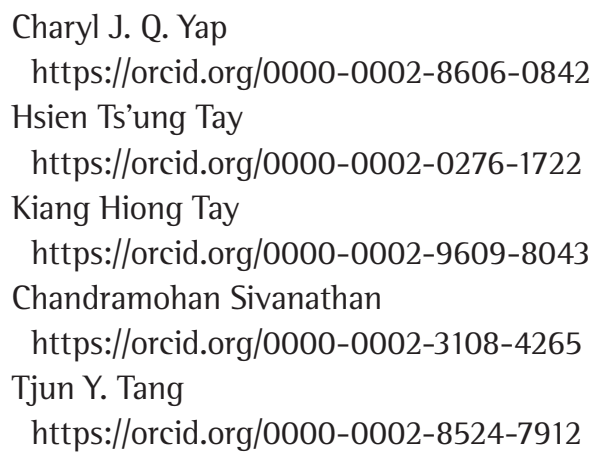

\section{AUTHOR CONTRIBUTIONS}

Concept and design: TYT. Analysis and interpretation: TYT, SXYS. Data collection: SXYS, AP, TTC, CJQY, HTT, KHT, CS. Writing the article: TYT, SXYS. Critical revision of the article: TYT. Final approval of the article: TYT. Statistical analysis: SXYS. Obtained funding: none. Overall responsibility: TYT.
1) Song P, Rudan D, Zhu Y, Fowkes FJl, Rahimi K, Fowkes FGR, et al. Global, regional, and national prevalence and risk factors for peripheral artery disease in 2015: an updated systematic review and analysis. Lancet Glob Health 2019;7:e1020-e1030.

2) Tang T, Kum S, Ho P, Tan Y. Peripheral vascular disease and endovascular therapy in Singapore. In: Dardik A, editor. Vascular surgery: a global perspective. Cham: Springer; 2017. p. 8190.

3) Yeo TC, Chan YH, Low LP, Venketasubramanian N, Lim SC, Tay JC, et al. Risk factor profile and treatment patterns of patients with atherothrombosis in Singapore: insight from the REACH Registry. Ann Acad Med Singap 2008;37:365-371.

4) Mills JL Sr, Conte MS, Armstrong DG, Pomposelli FB, Schanzer A, Sidawy AN, et al.; Society for Vascular Surgery Lower Extremity Guidelines Committee. The Society for Vascular Surgery
Lower Extremity Threatened Limb Classification System: risk stratification based on wound, ischemia, and foot infection (WIfl). J Vasc Surg 2014;59:220-234.e1-2.

5) Ramkumar N, Suckow BD, Brown JR, Sedrakyan A, Cronenwett JL, Goodney PP. Sex-based assessment of patient presentation, lesion characteristics, and treatment modalities in patients undergoing peripheral vascular intervention. Circ Cardiovasc Interv 2018;11:e005749.

6) Soon SX, D'Çruz R, Yap CJ, Tay WL, Chng SP, Choke ET, et al. The modified frailty index-11 predicts medium-term outcomes after endovascular revascularisation for chronic limb threatening ischaemia in Asian patients. Vascular 2021. doi: 10.1177/1708538120988228. [Epub ahead of print]

7) Lowry D, Saeed M, Narendran P, Tiwari A. A review of distribution of atherosclerosis in the lower limb arteries of patients with diabetes mellitus and peripheral vascular disease. Vasc Endovascular Surg 2018;52:535-542.

8) Park Y, Rha SW, Choi B, Choi S, Byun J, Mashaly A, et al. Increased long-term adverse outcomes of diabetic patients undergoing endovascular therapy for peripheral arterial disease are attributable to distal lesion distribution. Circulation 2017;136(Suppl 1):A20333.

9) Qiu YH, Yu GF, Zhou HH, Xia HW, Chen L, Chen HT, et al. Determination of risk factors and establishment of a prediction model for immediate technical failure during endovascular treatment of femoropopliteal occlusive disease. Ann Vasc Surg 2018;48:3544.

10) Singh GD, Brinza EK, Hildebrand J, Waldo SW, Foley TR, Laird JR, et al. Midterm outcomes after infrapopliteal interventions in patients with critical limb ischemia based on the TASC 11 classification of below-the-knee arteries. J Endovasc Ther 2017;24:321-330. 